\title{
Chapter 6. Chains as proper enrichment for intensively-farmed pigs?
}

\author{
Marc B.M. Bracke \\ Wageningen UR Livestock Research \\ marc.bracke@wur.nl
}

Originally published and to be cited as:

Bracke MBM. Chapter 6. Chains as proper enrichment for intensively-farmed pigs? In: Spinka M, editor. Advances in Pig Welfare: Elsevier (2017).

Abbreviations used: $\mathrm{AMI}=$ animal-material interactions, $\mathrm{IND}=$ intelligent natural design

\begin{abstract}
This chapter primarily compiles work in which the author (Marc Bracke) has been involved with providing science-based decision support on the question of what is proper enrichment material for intensively-farmed pigs as required by EC Directive 2001/93/EC. Proper manipulable material should primarily provide occupation (i.e. reduce boredom), and preferably reduce tail biting.

The RICHPIG model was built expressing enrichment value as a score on a scale from 0 to 10. Metal objects like short metal chains had the lowest score. Subsequently, the Dutch government banned the use of metal chains, and most Dutch pig farmers attached a hard plastic ball or pipe to the prevalent, short metal chain. Unfortunately, our on-farm observations repeatedly suggested that this 'enrichment' may have reduced pig welfare, rather than improving it as intended by the Directive.

So-called AMI (animal-material interaction) sensors can be used to (semi-)automatically record object manipulation by attaching a motion sensor to hanging objects. Exploratory data are presented to, directly and indirectly, record enrichment value. AMI-sensors may provide objective, flexible and feasible registration tools of enrichment value, but their application is still rather demanding.

That the enrichment value of short metal chains can be improved upon, e.g. by providing branched chains. Essentially, this entails making chains longer, preferably reaching until the floor, and making them more readily available in a pig pen. To facilitate the process towards proper enrichment the principle of intelligent natural design (IND) is proposed. IND entails organising a repeated selection process of the (currently) best-available enrichment material so as to gradually reduce pig boredom and enhance the opportunities for the rearing of pigs with intact tails. IND should start with basically all pig farmers implementing promising enrichment like the branched-chain design on their farms as soon as possible, followed by conducting small-scale on-farm experiments to compare and improve enrichment through sharing of available knowledge. Suggestions are given as to how and why this novel approach can be implemented to solve persistent animal-welfare problems like providing proper enrichment for intensively-farmed pigs.
\end{abstract}

Keywords: Growing-fattening pigs, weaners, enrichment, animal welfare, chains, toys, policy making, decision support, intensive farming

\subsection{EC Directive}

Directive 2001/93/EC states that: 
Pigs must have permanent access to a sufficient quantity of material to enable proper investigation and manipulation activities, such as straw, hay, wood, sawdust, mushroom compost, peat or a mixture of such, which does not compromise the health of the animals (Article 4 of the Annex, EC (2001)).

This may sound like a clear requirement, but in fact it is not. This is because the Directive's formulation contains words like 'proper' and 'such as'. To implement the Directive, therefore, it is necessary to answer the question of what are proper enrichment materials for pigs. This has proven to be a difficult question (CIWF, 2008; 2014). It is still largely unresolved despite the fact that the Directive should have been implemented in all EU member states as of January 2003. More recently, the European Commission also drafted new guidelines, both in 2014 (EC, 2014) and in 2016 (EC, 2016), trying to clarify the matter. The new guidelines are ambitious, but not obligatory and lacking detailed specifications. Hence their effective implementation may generate considerable challenges. Science-based decision support to improve pig enrichment, therefore, is urgently needed.

This chapter aims to address the question what is proper enrichment for intensively-farmed pigs as implied by the Directive. It focuses on enrichment materials that aim to provide 'proper investigation and manipulation activities'. Such manipulable materials are primarily intended to provide occupation and reduce boredom. Boredom results from the fact that pigs, which have evolved to spend a considerable proportion of their time exploring and foraging (typically by rooting) have little else to do in barren pens in intensive farming systems except for eating (briefly) and sleeping. This frustration of the behavioural needs of exploration and foraging leads to abnormal, harmful social behaviours especially in the form of tail biting in growing/fattening pigs (SVC, 1997) as well as to stereotypies such as bar-biting of sows in stalls. In accordance with this all materials listed in the Directive (straw, hay, wood, etc.), except sawdust, have been shown to be able to provide occupation and/or reduce abnormal biting behaviour (SVC, 1997; Bracke et al., 2006). It is worthwhile noting here that tail biting is a multifactorial problem (see Chapter 5), with a rather unpredictable and variable occurrence. This makes it difficult to study (EFSA, 2007b) such that it is virtually impossible to use a reduction in tail biting as the main criterion of whether a (new) material is to be regarded as proper enrichment. Hence, the primary objective of proper enrichment material is to provide occupation, also called 'animal-material interactions' (AMI). The secondary objective is to prevent abnormal/psycho-pathological biting behaviours like ear, flank and tail biting, and such that in particular the mutilation of routine tail docking, which has also been banned in the Directive, is no longer needed. Two additional requirements for what may be considered proper in accordance with the Directive are that manipulable materials must be (a) permanently available and (b) not compromise pig health.

In this chapter I address the issue of what is proper enrichment material for intensivelyfarmed pigs from my perspective through the various projects I have been involved with. Based on that experience I will formulate practical recommendations for the short-term implementation of the so-called branched chain design and the longer-term application of what I have labelled 'Intelligent Natural Design' (IND).

\subsection{RICHPIG}

In order to help the Dutch ministry decide what may be regarded as proper enrichment, we reviewed the scientific literature (Bracke et al., 2006), consulted experts (Bracke, 2006) and developed the RICHPIG model (Bracke et al., 2007a; 2007b; Bracke, 2008). The model contains 130 enrichment materials and 30 weighted assessment criteria to determine overall enrichment value (Bracke, 2008).

Figure 6.1 shows the conceptual framework underlying RICHPIG. 


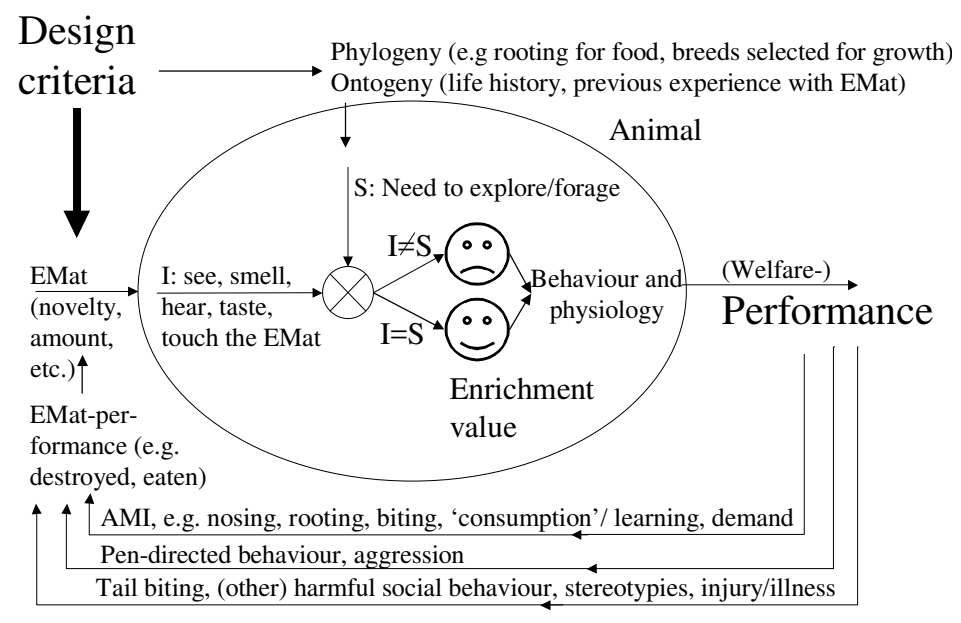

Figure 6.1 Schematic representation of the conceptual framework for assessing environmental enrichment for pigs. EMat: Enrichment material; AMI: animal-material interactions; I: Istwert, the environment as perceived by the animal; S: Sollwert, setpoint or norm (modified homeostatic model after Wiepkema (1987) and (Anonymous, 2001)). (Figure from Bracke (2008), permission granted by UFAW).

Progressive feedback loops in the framework indicate that the animal's welfare is good when proper enrichment satisfies the pigs' need to explore and forage. When the enrichment is deficient, the animals will redirect their attention and show pen- and pen-mate directed behaviour. Note that this may imply a mechanism resembling the principle of communicating vessels (connected containers filled with liquid; see Wikipedia (2016c)). In accordance with this principle pigs may distribute their (motivation for) exploratory behaviour (the liquid) depending on the quality of the manipulable 'materials' available to them (cf Bracke et al. (2012)). Eventually, an outbreak of tail biting may occur, potentially evoking a positive feedback loop (an escalating outbreak) leading to cannibalism when no 'proper enrichment' is provided buffering and/or eliminating the (primary) cause/stressor.

The conceptual framework emphasises that the pigs' need for enrichment is affected by their evolutionary and life history. Pigs have evolved to root in forest soil using their rooting disks, mainly involving downward, floor-directed behaviour. In other words, pigs are not built to reach up to straw racks or twist their heads to bite vertical wooden logs. Similarly life history, e.g. rearing on straw, may enhance the pig's need for exploration and put the animal at risk when access to straw is subsequently denied (Munsterhjelm et al., 2009). In addition, the experience of tail biting may further enhance the need for exploration (of tails and enrichment) as indicated by the tendency of tail-biting outbreaks to escalate (Fraser, 1987a). The conceptual framework also provides the ordering principle for RICHPIG's assessment criteria. In total RICHPIG has 30 assessment criteria, classified as object-design criteria (e.g. novelty and accessibility), behavioural elements (e.g. nose, root, chew), biological functions/needs (explore and forage), manipulations (i.e. object- and penmate-directed behaviours), other (non-manipulative) consequences (e.g. aggression and stress) and objectperformance criteria (e.g. destructibility and hygiene) (Bracke, 2008). Assessment criteria that generated the highest weightings included (known effects on) tail and ear biting, animalmaterial interactions (AMI) and rooting (Bracke et al., 2007b). In the final model weighting factors ranged from 12.5 for (being able to reduce) 'Tail and ear biting' to 1.2 for 'Movability' (Bracke et al., 2007b; Bracke, 2008) (see also Van de Weerd et al. (2003)). 
A subset of 64 materials was evaluated by 9 international pig-welfare experts (Bracke et al., 2007a). Materials generating the lowest scores (on a scale from 0, low, to 10, high) included a mirror, a concrete block, a rubber mat, a minimal amount of straw (!), a mineral block, a heavy plastic ball, a chain (with or without hard wood attached to it), a rubber-hose cross, a free toy (sow neck tether), a hanging car tyre, a bucket, an additional operant feeder, a fixed wood block, bite rite (i.e. a plastic cone with 'tail-like' projections), and a knotted rope (all median expert scores $<2.5$ ). Materials that generated high scores included forest soil, roughage, fodder beet, maize silage, grass (silage), whole straw with chopped beet roots, with maize silage or with additional feed, a bale of straw, long straw with fir branches and straw with forest bark and branches (all median expert scores $>=7.0$ ). The experts suggested a score of 5.0 as the minimum score they considered acceptable enrichment, and this included materials such as compost from a dispenser, straw pellets (loose or from a plastic dispenser) and straw in a metal basket (cited from Spoolder et al. (2011)).

Based on the RICHPIG study and a follow-up study initiated by the pig sector (Ten HaveMellema and Van Gemert, 2006) also looking at economic consequences (Zonderland, 2007) the Dutch Ministry decided that a most minimal welfare improvement would be acceptable. As of July 2007 the Ministry no longer accepted the prevalent short metal chain, but it would allow such chain if it had some indestructible synthetic/plastic material attached to it (Verburg, 2007). Only car tyres were excluded because they may contain metal parts that can be ingested (LNV, 2007). In the years after 2007 Dutch intensive pig farmers, i.e. those not involved in the Better Life welfare scheme, gradually attached indestructible materials, esp. hockey-type balls and polyethylene pipe, to the end of the chain.

\subsection{Communication}

Our next project focussed on reducing tail docking, now involving the issue of 'proper enrichment' as one of many measures to prevent and treat tail biting, and (eventually) to keep the pigs' tails intact (Table 6.1). 
Table 6.1 Overview of communication time points concerning pig enrichment (including legislation drafting and implementation, and timing of research projects).

\begin{tabular}{|c|c|}
\hline Date & Event \\
\hline 1994 & Dutch legislation on pig enrichment (Barren pen no longer allowed; short chain is ok; Anonymous, 1994) \\
\hline Aug. 2001 & EC Directive issued on proper pig enrichment (EC, 2001) \\
\hline Jan. 2003 & EC Directive ought to have been implemented (EC, 2001) \\
\hline 2003 & NGO calls on Dutch Ministry of agriculture to enforce 1994 legislation to provide a chain (Bleijenberg, 2003) \\
\hline Aug. 2003 & Start of RICHPIG project (3yr; Verburg, 2007) \\
\hline May 2006 & Alarm letter of pig sector to ministry about enrichment (Ten Have-Mellema and van Gemert, 2006) \\
\hline 2006 & End of RICHPIG project \\
\hline 2007 & Project initiated by pig sector to weigh in other values (esp. economics; Zonderland, 2007) \\
\hline July 2007 & Dutch guidelines specified (Short chain is no longer sufficient; chain with ball or pipe is ok; LNV, 2007). \\
\hline 2008-2011 & Project 'Ending tail docking'/'Responsible tail management' \\
\hline 2008 & Farmer survey (De Lauwere et al., 2009) \\
\hline 2010-2011 & Information and tool box for farmers to deal with tail biting; prize contest (www.hokverrijking.nl) \\
\hline Sept. 2010 & $\begin{array}{l}\text { Dutch pig sector was informed about welfare deficit of ball/pipe and promising alternative (branched chain; } \\
\text { Bracke, 2010a) }\end{array}$ \\
\hline 2011 & $\begin{array}{l}\text { Farmers optimistic about pig enrichment (Questionnaire Livestock Fair) in relation to Better Life } \\
\text { RICHPIG calculations balls/pipe implementation in NL implied saving about } 71 \text { million euros at a loss of } 376 \\
\text { million enrichment-value life-points compared to softwood over the period 2003-2011. }\end{array}$ \\
\hline 2013-2016 & FareWellDock project (www.farewelldock.eu) \\
\hline 2015 & Enrichment (chain+ball/pipe) mostly implemented in NL (NVWA, 2015a, 2015b) \\
\hline March 2016 & New EC guidelines/recommendations on enrichment and tail docking (EC, 2016, 2016b) \\
\hline 2016 & Pig expert questionnaire confirms value of branched chain design (Bracke, Submitted) \\
\hline
\end{tabular}

In 2008 we conducted a telephone interview among 487 conventional and 33 organic pig farmers in the Netherlands (De Lauwere et al., 2009; Bracke et al., 2013). We found that conventional farmers mainly used metal chains (52-63\% of the farms) and hanging rubber or plastic balls (22-30 \%). Other reported materials were a ball or jerrycan loose in the pen: $15-$ $19 \%$; chain with plastic hose around it: $15-20 \%$; other plastic or rubber toys: $8-12 \%$. Nonsynthetic materials (wood, rope, straw, sawdust, woodshavings, roughage) were only used marginally (all $<<10 \%$ ).

We also made information about enrichment and tail biting available on the website called www.hokverrijking.nl (Dutch for 'pen enrichment'), and we developed a tool box for farmers to deal with tail biting. The website was also used in a separate project where the objective was to provide more proper enrichment in the outdoor run of organic pigs. Since the outdoor runs in organic farming are often rather barren enclosures with a slatted floor, the design challenge for providing proper enrichment in organic pens was found to be remarkably comparable to the challenges encountered in conventional pens.

In addition, a small questionnaire ( $\mathrm{n}=34$ pig farmers) was conducted on the hockey-type ball that had been implemented rather widely on pig farms in the Netherlands (Bracke, 2011d). It showed that pig farmers did not consider the investment in the balls acceptable, and they significantly lowered their appreciation of the welfare-benefits of the ball when they had such a ball in their own barn (compared to when they didn't). This suggests that the hockey-type balls raised higher expectations than were actually realised, both in terms of economy and pig welfare.

Furthermore, a compact questionnaire was also distributed at a livestock fair in the Netherlands in October 2011. As many as $72 \%$ of all respondents $(n=1687)$ regarded enrichment as an opportunity for livestock husbandry, and they expressed a very high (up to $95 \%$ ) level of optimism regarding environmental enrichment. This was probably related to the recent introduction of the Better Life (Beter Leven) welfare scheme of the Dutch Society for 
the Protection of Animals. This provided conventional livestock farmers with an opportunity for some additional economic benefit. For pigs it entailed providing some extra space (1.0 instead of $0.8 \mathrm{~m}^{2} / \mathrm{pig}$ ), enrichment materials (e.g. a straw briquette), minimum tail length $(>2.5$ $\mathrm{cm}$ at docking) and the rearing of intact boars. The types of enrichment provided in the Better Life scheme, however, could be optimised. In particular the straw briquette was introduced, made up of a cylinder of pressed, short-chopped straw held in a PVC holding pipe. Like the hockey ball, the briquette enrichment probably looked, in my opinion, nicer than it really was. Apparently, farmers seemed to be providing a minimal amount of straw by restricting the pigs' access to the straw briquette (e.g. by making it protrude minimally from the PVC holding pipe (Van den Berg, 2016; Weber, 2016)) and sometimes failing to de-block or refill containers timely. As indicated by the RICHPIG model and consulted experts a minimal amount of straw has very limited welfare benefits to the pigs (average expert score $<2.5$ where 5.0 would have been acceptable). It may even reduce welfare due to inducing frustration and competition.

Hence, when considering the issue of what is proper enrichment, it is important to be aware of preconceived ideas, potential bias and anthropomorphism. The term enrichment suggests a welfare improvement, or even a welfare bonus, but that may at times be little more than a human expectation or perception. Furthermore, the term enrichment (or 'better life') can be a euphemism. When a material improves welfare, it may formally be correct to label it as enrichment, but when the pigs are otherwise still kept under most barren conditions at a very low level of overall welfare, it would be more appropriate to use the term 'de-barrenment' instead of enrichment. Some researchers also prefer to avoid the term enrichment altogether, because the term is too general and because, rather than providing something 'extra', pig enrichment deals primarily with manipulable materials which the pigs can use as a minimum fulfilment of their need to root and explore (A. Valros, pers. comm.).

Another example of human perception of pig enrichment, in which I have been involved, is the computer-game for pigs, called Pig Chase (HKU, 2011; Van Peer, 2012; Anonymous, 2012b). Its primary objective was to trigger ethical thinking about pig farming. In addition, what I found interesting about the idea of a computer game for pigs is that it could challenge the pig's cognitive abilities, in my view a much neglected aspect of pig enrichment. Pig Chase shows pigs interacting with a gamer via an iPad. When the pig follows a red dot controlled by the gamer, it is 'rewarded' by fireworks. This is not proper enrichment for pigs. Fireworks are nice for people. Similarly, balls are nice for people (esp. because they are associated with sports), and chains are not perceived as nice. In the perception of the general public metal chains are more likely to be associated, perhaps unconsciously, with prisons and slavery, and, for those who are a bit more knowledgeable, with the stereotyped chain-chewing seen in tethered sows (Schouten and Wiegant, 1996). Since these underlying emotions and associations may have contributed to the general appreciation of balls and lack of appreciation of chains as pig enrichment, it is important to be aware of the distinction between our human perceptions and what is important for the pigs themselves.

\subsection{On-farm observations}

In on-farm work, often with the help of students, the poor state of enrichment in conventional pig farming, as already indicated by the RICHPIG work, was confirmed. I had seen farms, some of them suffering from high levels of tail biting, where the hockey-type balls were dry and collecting dust, and where pigs were frustrated when they tried to grab the ball (see also Figure $6.3 \mathrm{~b}$ later in this chapter). Also bigger balls provided loose on the floor can often be seen lying in the dunging area without any persistent enrichment value to the pigs. Our more systematic (scientific) observations in pregnant sows, weaned piglets and growing/fattening pigs kept in different housing systems repeatedly indicated that the pigs 
were interacting less (!) with the chain when relatively hard, indestructible balls or plastic/synthetic tubes had been attached to the end of the chain (Ettema, 2010a; 2010b). Perhaps chain manipulation reduces stress, as has been shown for the early phases of chain chewing in tethered sows (Schouten and Wiegant, 1996). Hence, and as farmers sometimes suggest, perhaps interacting with the end of a metal chain is comparable to chewing gum or playing with a pencil in human adolescents. When the chain is on the floor, it allows some form of rooting on the chain, and the interaction may be comparable to stone chewing which is prevalent in outdoor sows (Horrell et al., 2001). Most farmers opted for rather indestructible (and hence cost-efficient) materials (balls and pipe), e.g. by hanging them a bit higher when they had to be replaced so they are less easily destroyed. Thus the 'add-ons' were found to be mostly inferior compared to the flexible end of a freely available metal chain. Plastic materials are probably better when they are more destructible (e.g. as indicated by Courboulay (2006; 2011). However, destructible plastic materials (tylene, alkathene, pvc, etc.) need replacement and they pose an environmental risk as they are ingested or they are degraded by the pigs and end up in the slurry pit (Spoolder et al., 2011).

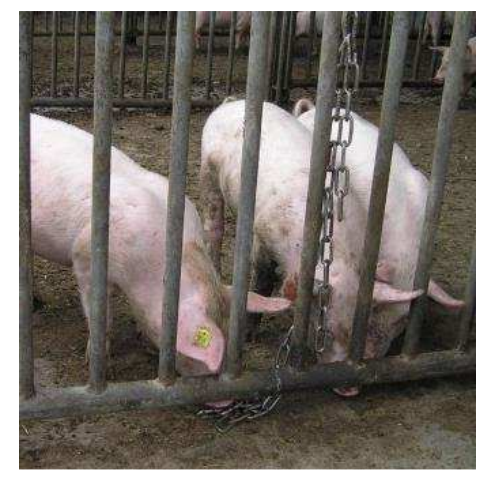

Figure 6.2 Branched chain i.e. a chain reaching till floor level where the chain may be 'rooted' or manipulated while lying down, and to which two short pieces of chain have been added such that ends of a chain are available at nose height to pigs of different sizes or age groups for manipulation while standing. (Note, however, that this is a c-chain, not a stainless steel anchor chain, which is recommended).

We also found that pigs interacted more and for a longer period of time with a branched chain (Figure 6.2) compared to various other enrichment devices such as a chain with hard, hockeytype plastic ball attached to it, a loose ball on the floor, a large wood block, a short chain hanging from the ceiling, and a short chain attached close to the floor (Wind, 2012). With branched chains pigs have access to the ends of a chain both at floor level and at nose height. This gives pigs the opportunity to choose, and we found that pigs interact more than twice as often with the chain end lying on the floor than as with the pieces of chain ending at nose height (Wind, 2012). In other words, pigs seem to prefer to 'root' on the chain that is lying on the floor, and they can manipulate such a chain while the pigs themselves are lying on the floor (which is not possible with the conventional, short chain ending at nose height).

Even organic pigs with access to straw bedding have been observed to interact extensively with branched chains and similar designs (e.g. a round chain with rings for 'rooting' (which they didn't use) and branches (which they did)). This implies branched chains may have enrichment value even when straw is provided, despite the fact that straw has been shown to be used much more extensively (Scott et al., 2007) and is known to reduce tail biting (Zonderland et al., 2008). It is not expected that branched chains will substantially reduce tail biting. This remains to be shown, however, and longer chains have been shown to substantially reduce ear biting under compromised conditions of limited access to a water nipple (De Grau et al., 2005)). However, branched chains do provide substantially enhanced 
(longer and supplemented quality) occupation (AMI) for the pigs compared to the conventional, short metal chain. This makes them suitable candidates for what may be regarded as proper enrichment material for intensively-farmed pigs. The indestructible materials I have encountered are not better, most often worse, than the short metal chain, thus worse than a branched chain. By contrast, compared to alternative, more destructible materials (like ropes, jute, soft wood, substrates), branched chains are probably, but not always, used less (Bracke, 2007b; Ettema, 2010a). However, branched chains are much more feasible (lower cost, less labour for maintenance, less risk of blocking of the manure system), more hygienic (reduced health/biosecurity risk), probably better for the environment, and they provide a much better guarantee of being permanently available as required by the EC Directive, and (hence) they also much better allow for verification of actual compliance. Furthermore, branched chains can be specified much more accurately and uniformly than any of the destructible alternatives (and such detailed specifications are given below). This is because destructibility is difficult to measure objectively, and because many qualities codetermine the suitability of destructible materials (e.g. wood, straw and rope come in many different types, sizes and processing stages/freshness). In other words, branched chains are much more suitable candidates for being used as a standard or benchmark (reference point) against which other materials can be compared. Note, however, that such a benchmark for proper pig enrichment, doesn't entail it must be proper, i.e. provide a sufficient level of occupation, in and of itself. Expert opinion strongly suggests branched chains should be regarded as providing almost proper enrichment (Bracke, Submitted). These chains, therefore, provide a most suitable starting point for further enrichment, also because other objects can be attached to the branched chains. Furthermore, even when branched chains are supplemented by substrates on the floor, such as roughage or straw, the pigs have been found to remain interested in the branched chain, providing a background enrichment that will remain permanently available, even when the substrates or other destructible materials are not (Figure $6.3)$.

Several important conclusions can be drawn from our modelling work and on-farm observations:

1. A short metal chain without attachment consistently elicited more manipulation and investigation activities by the pigs than the same chain at the end of which a rather indestructible hockey-type ball or pipe had been attached. Since pigs clearly prefer to manipulate the end of a chain over a ball and pipe, such materials are not proper enrichment materials for pigs (see also (EFSA, 2007a; 2007b; Spoolder et al., 2011)). Such 'enrichment' is more properly referred to as impoverishment.

2. The short chain can be improved upon, esp. using a branched-chain design reaching in part down to floor level (see also Parmentier (2007)).

3. The RICHPIG model was designed to support decision making to implement the EC Directive in the Netherlands. By the end of 2010 it became clear that welfare had more likely been reduced and that branched chains provided a possible solution (Bracke, 2010b). In 2011 I quantified pig welfare in the Netherlands using the RICHPIG model together with available data about the numbers of pigs raised in the Netherlands (CBS, 2011) and economic data about enrichment materials (Zonderland, 2007). I calculated the economic investment and welfare discrepancy between chains with/without balls and pipe on the one hand and a softwood beam on the other between 2003 and 2011 (when I did the calculations (Bracke, 2011d)). The soft-wood was taken as an example of a more proper (though not fully proper) enrichment material than the plastic objects (Bracke et al., 2007a; Bracke, 2008; EC, 2016). My calculation over the period 2003-2010 resulted in a total of 70 million years of pig life experiencing a welfare discrepancy of 376 million enrichment-value life-points. This is 
equivalent to roughly 140 million pigs experiencing a reduction of 2.7 enrichment/welfare RICHPIG points for the balls/pipes compared to the soft-wood beam provided in their 6month life span each. In addition, I found that the Dutch pig sector had invested about 4.7 million euros in the balls and pipes, whereas the soft-wood beam was estimated at 76 million Euros (Bracke, 2011d). This illustrates how welfare models based on semantic modelling like the RICHPIG model and/or expert opinion scores can not only be used to support future decision making, but also to calculate welfare effects (here, a lifetime 2.7 RICHPIG points improvement for a cost of 0.5 euro per pig) related to decisions that have been made in the past, as well as welfare benefits that may be obtained by pursuing suggested welfare solutions.

These findings also strongly emphasise the need for empirical observations to underpin claims about enrichment. New materials should preferably be tested properly before they are released onto the market. This led us to examine feasible and flexible tools, so-called AMI-sensors, to assess enrichment value more objectively.
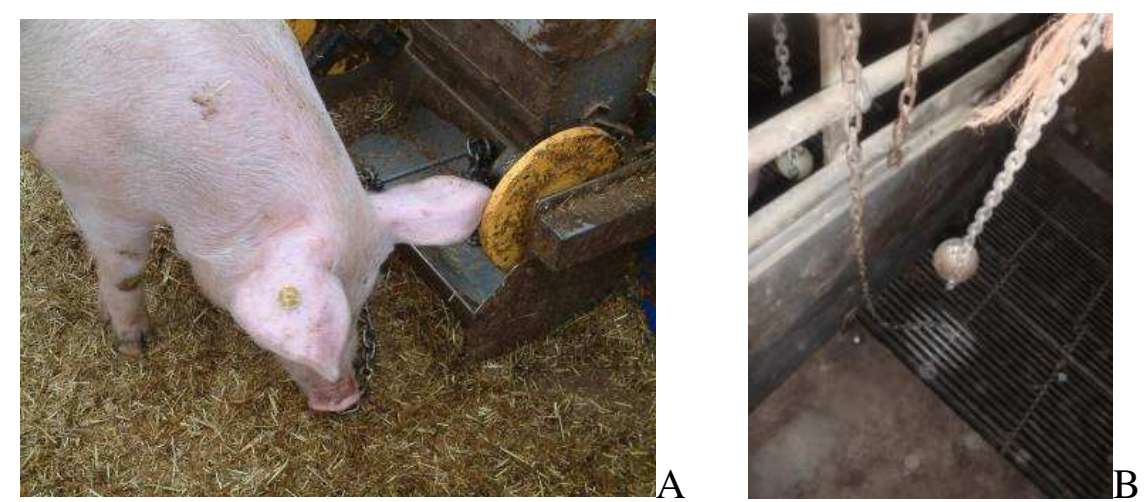

Figure 6.3a Pig manipulating an anchor-type chain on the floor covered with straw. The feeder (actually a rooting bin) in the picture was permanently empty and not used for feeding or rewarding the pigs. Note that the chain is a stainless steel anchor-chain, which has more rounded links than the cheaper and apparently less preferred c-chain (Photo by Herman Vermeer).

Figure 6.3b Balls dry and collecting dust near a short chain and a chain reaching until the floor. Note how the short chain is rusty (hanging too high) and that the metal slats are shining indicating intensive use of the chain on the floor.

\subsection{AMI sensors}

\subsubsection{Introduction}

The term AMI-sensor was coined by Johan Zonderland. AMI stands for animal-materialinteractions. AMI-sensors may record object use in various ways. Zonderland et al. (2001) used an electrical circuit to detect AMI in different hanging materials that were changed weekly. They found renewed interest immediately after introduction, indicating that novelty is important for pig enrichment. Earlier, Grandin had used mechanical counters to record levels of toy use (Grandin, 1989). I also used mechanical counters, e.g. to show that repellents, such as Dippel's oil and Stockholm tar, can reduce the pigs' interest in a novel rope (Bracke, 2009). Similarly, soiling with faeces reduced rope manipulation, while making the rope more destructible enhanced rope manipulation (Bracke, 2007b). As of 2013 the FareWellDock project enabled further work on AMI-sensors. To validate their use we explored whether we could determine enrichment value either directly or indirectly. Direct measurements record movement of the enrichment materials to which the AMI sensors have been attached. Indirect 
measurements are intended to detect an effect of one enrichment (e.g. substrate) by recording AMI of another material (e.g. a rope). Based on the principle of communicating vessels, indirect AMI measurements assume that if the enrichment material of interest (e.g. substrate) has a higher enrichment value, it should reduce the interest in the recorded material (e.g. rope). In the next four subsections, examples are given of the use of AMI sensors in experiments that investigated the effects variables such as feed restriction, tail and flank biting, streptococcus infection, and maize silage provision on the use of enrichment materials.

\subsubsection{Food restriction prior to anaesthesia}

We used Icetag loggers to record AMI directly by attaching the loggers to a jute sack (reaching until the floor) and a bare metal chain ending at nose height. Both materials were simultaneously present in a pen with 2 pigs. The pigs were also subjected to a brief (12-24h) period of food deprivation prior to propofol anaesthesia. Three such incidences were logged. In accordance with expectations (Feddes and Fraser, 19941; Ursinus et al., 2014b), the pigs interacted much more with the destructible jute sack than with the indestructible chain (Figure 6.4). In addition, on the day after anaesthesia AMI values seemed depressed. In contrast to expectation, the 3 periods of feed deprivation prior to anaesthesia did not show clear signs of enhanced AMI. Perhaps habituation was incomplete, or the pigs may have been (re-)directing exploratory behaviour towards the (limited amount of) sawdust that was provided on the floor. These exploratory data may well be among the first minute-by-minute recording of enrichment AMI in pigs.

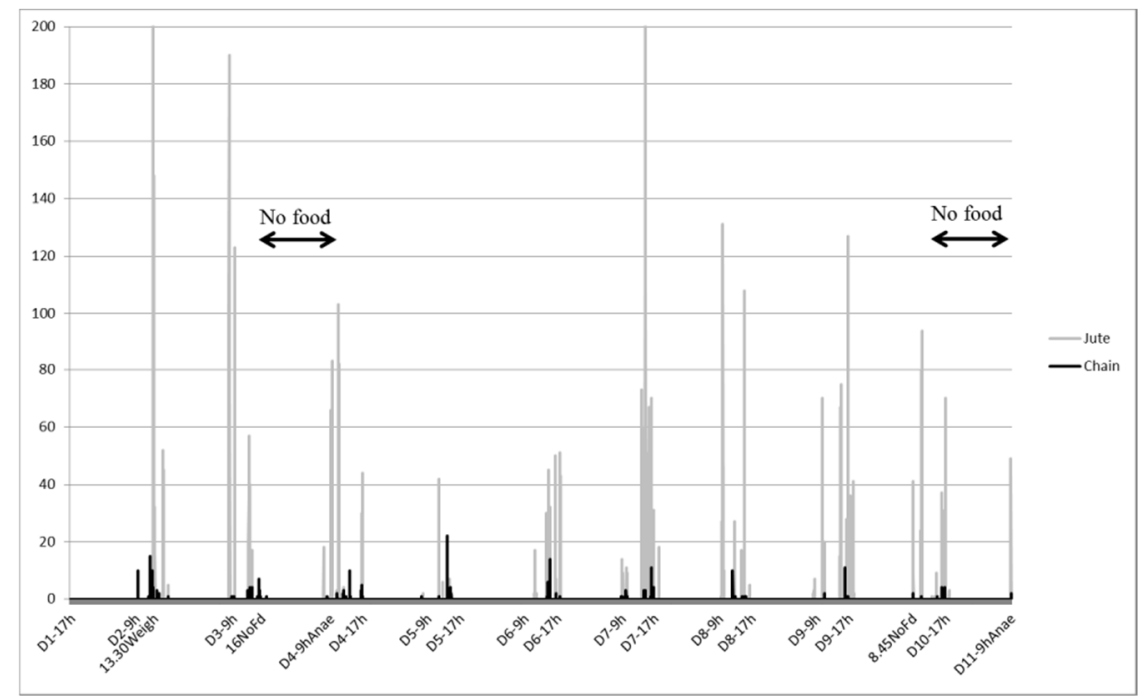

Figure 6.4 Icetag Motion Index, expressed as a value ranging from 0 to 280 and from 0 to 22 for jute sack and chain respectively, on a minute by minute basis over 11 days in a pen with 2 pigs. D: day number - time (h: hour); NoFd: no food (also indicated by arrows), e.g. $16 \mathrm{NoFd}$ $=\mathrm{Fd}$ taken away at $16 \mathrm{~h}$, to be available only in the afternoon of the next day (after anaesthesia); Anae: Animals under anaesthesia that day (D4 and D11); D11: anaesthesia followed by euthanasia.

\subsubsection{Flank and tail biting}

On one farm we did a matched control study on all pens with flank and tail biting (Bracke and Ettema, 2014). Mechanical counters were used to test the pigs' propensity to interact with a novel rope in biter and control pens. On the farm $20 \%$ of the pens had pigs with biting wounds; $5.4 \%$ concerned tail biting and $14.3 \%$ showed flank biting. In accordance with earlier findings (Bracke, 2009), the pigs lost interest in the ropes over time. Most importantly, however, we showed that biter pens interacted significantly more with the ropes compared to 
controls. This may indicate an enhanced need for enrichment when biting wounds are present, thus perhaps complicating the principle of communicating vessels. In other words, what is proper enrichment under normal conditions (in control pens) may not be adequate enrichment once abnormal biting behaviour has resulted in tail, ear, leg or flank biting wounds.

\subsubsection{Streptococcus infection}

While abnormal biting seems to be associated with an increased need for enrichment, sickness, by contrast, may reduce it. To explore the effect of sickness on AMI we (the author in collaboration with de Greeff et al.) attached IceCubes (IceRobotics, UK) to a metal chain ( $n=6$ pens with 5 pigs per pen) to record AMI before and after an experimental infection with Streptococcus (either S. suis or S. pneumoniae, high/low dose, intranasally/intravenously (de Greeff et al., 2016)).

AMI appeared to be reduced shortly after the infection (Figure 6.5). In other words a streptococcus infection may reduce the pigs' propensity to interact with a chain, perhaps reflecting the experience of feeling sick (Bracke, 2016b). This indicates that AMI-sensors could perhaps be(come) of value in an early warning system for disease, and thus help in early diagnostics and reduction of the use of antibiotics.

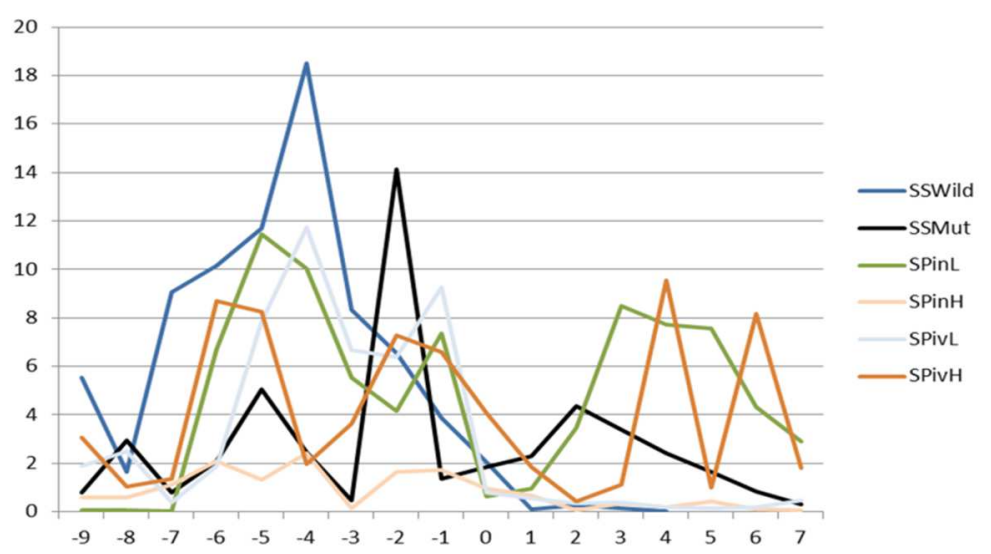

Figure 6.5 Average motion index values per day for the 6 treatments (1 pen per treatment). SS: S. suis; Wild: wild strain; Mut: Mutant strain; SP: S. pneumonia; iv: intravenous; in: intranasal; L: low dose; H: high dose. Day 0 is the day of infection.

\subsubsection{Maize silage}

Two related experiments by Aarnink et al. investigated the effects of maize silage in the socalled Starplus barn and the thermally-controlled so-called APF barn (Air Pathogen Free barn using overpressure) at the pig research station (Swine Innovation Centre, Sterksel). The main objective of the AMI recordings was to detect indirectly whether maize silage had enrichment value by logging AMI of ropes (Bracke et al., 2014; Bracke et al., 2015 (unpublished)). In addition, we looked at some variables like time of day, room temperature and gender, and directly compared AMI of ropes and hockey-type balls.

In the Starplus barn (Verdoes et al., 2014) pigs are provided with additional space, roughage and outdoor access to enhance pig welfare. We found that finishing pigs in the Starplus barn provided simultaneously with chopped straw and maize silage on the floor were interacting with this roughage more than pigs provided with chopped straw only. This effect lasted for about 30 minutes. Providing maize silage, however, had little or no effect on directlyobserved behaviours (general and exploratory behaviours), nor did it have an overall effect on toy (esp. rope) manipulation as measured by the AMI-sensors. Furthermore, in both Starplus and APF barns, and in accordance with expectation, the AMI-sensors confirmed that pigs 
were more interested in the sisal rope than in a hard-plastic, hockey-size ball hanging on a metal chain. In the APF barn rope manipulation also appeared to be affected by maize-silage enrichment in that on some days AMI was reduced when maize silage was provided.

Furthermore, other variables like gender, (time of) day and room temperature seemed to play a role, e.g. more reduction of rope manipulation due to maize silage at normal compared to low temperatures (Bracke et al., 2015 (unpublished)). Overall, while these moderate amounts of maize silage (0.17-0.25 kg/pig/day) seemed to have some beneficial effects on pig welfare, we only partially managed to detect this using indirect AMI-sensors on ropes, and background variables seemed to complicate the interpretation of AMI recordings. The number of pens per treatment was rather low, however, and perhaps the AMI sensors are not as sensitive as we would like, or the enrichment of maize silage is not substantial enough to be detected using indirect AMI recordings (however see Bracke and Spoolder (2007b)).

\subsubsection{Straw}

A semi-automated novel rope test also failed to show an effect of background enrichment (straw/no straw) or gender (boars/barrows) on AMI recorded indirectly as novel rope manipulation in the Comfort Class barn (de Greef et al., 2011; Vermeer et al., 2014). Again, the number of pens was rather low ( $\mathrm{n}=6$ per treatment) (Ettema, 2010a). In these pens $(\mathrm{n}=216$ growing pigs in 12 pens; $1.67 \mathrm{~m}^{2} / \mathrm{pig}$ ) 3 types of enrichment materials (short chain, hockeytype ball on a short chain, wooden plank on the floor) were weekly rotated. Behavioural observations showed that the wood on the floor was used much more than the hanging chain. More interestingly, the chains without balls were used more than the same chains with balls (Ettema, 2010a). While there was no effect of background enrichment (straw vs no straw) on toy use, we did find an effect of the use of automated rooting bins (cf Figure 3, not containing any food reward, so functioning as a kind of AMI-sensors): Pigs in straw pens interacted less with the rooting bins. This suggests that AMI-sensors, i.e. rooting bins, can indirectly record enrichment value (of straw), perhaps by virtue of the principle of communicating vessels between the rooting bins and straw. In accordance with this principle, rooting bins were also used more by the end of the week in which a toy (wood, chain, ball) was present compared to shortly after object rotation, when the toys were novel and attracted more interest. So perhaps the rooting bins did not only function as an AMI-sensor, but also as permanently present enrichment material attracting a variable interest depending on background conditions (straw/no straw; novel/familiar toy). In this way the rooting bins themselves may even have acted as a kind of buffer, reducing the likelihood of picking up the background enrichment using the novel rope as an indirect AMI test. Using a subjective scale of biting intensity/severity, we also found that pigs without straw would bite the observer more severely than pigs kept on straw (and in another study we found that biter pigs in tail biting pens were biting the observer who was present in the pen the hardest). Furthermore, biting wounds (but not fighting wounds, i.e. deep scratches) were only observed in the pens without straw, and more tail wounds were found in pens without straw. These findings, again, seem to confirm the hypothesis of communicating vessels, indicating that enrichment value of an object (the level of AMI it attracts) may be affected by the enrichment quality of other types of enrichment provided in the pen. In other words, the more barren a pen becomes, the more important the enrichment value of an enrichment material like a metal chain (or another pig).

\subsubsection{Short and (a bit) longer chains in poor and (really) rich rearing conditions}

Finally, in an experiment by Van Dixhoorn et al. (2016) we did seem to be able to detect a difference between rich and poor pens (4 pens per treatment; see example pens in Figure 6.6a and 6.6b) using indirect AMI measurement of two chains hanging in each pen (Bracke, 2016a). Young pigs in poor pens were more interested in the chains than pigs in (very) rich 
pens. The poor pens were conventional farrowing and weaner pens. In the rich pens the pigs were provided with extra space, compound enrichment (straw, peat, woodshavings, jute and branches) and social rearing ( 2 farrowing pens were joined after 1 week). This indicates that AMI-sensors (IceCubes, IceRobotics, UK) may be able to detect a (substantial) contrast in background enrichment in accordance with the principle of communicating vessels. The contrast between chain AMI of rich and poor pens, however, was less pronounced in the weaner pens than in the farrowing pens.

Another noteworthy finding was that in poor pens short chains (ending at nose height) appeared to be manipulated less than $10-15 \mathrm{~cm}$ longer chains. The longer chains seemed to be better, even without reaching the floor. This was esp. the case in the farrowing pens where the chains were hanging against the back wall and thus much less likely to be set in motion by the pigs' locomotor activity in relation to either enrichment level (more/less space) or chain length. This may indicate that the conventional short chain may even be improved upon by letting it reach a bit further down.

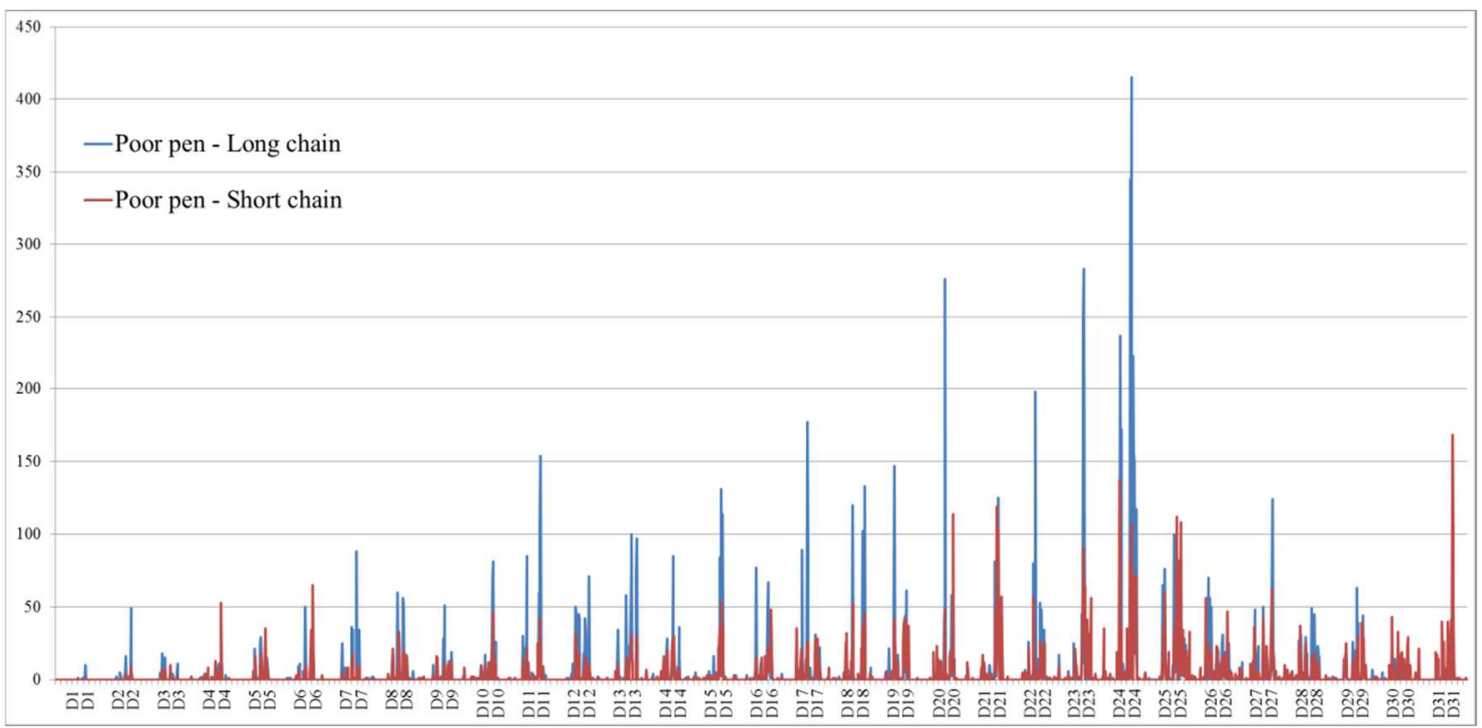

Figure 6.6a Motion Index values over 31 days in the farrowing pen for a short (red) and somewhat longer (blue) metal chain in a poor pen (conventional farrowing pen).

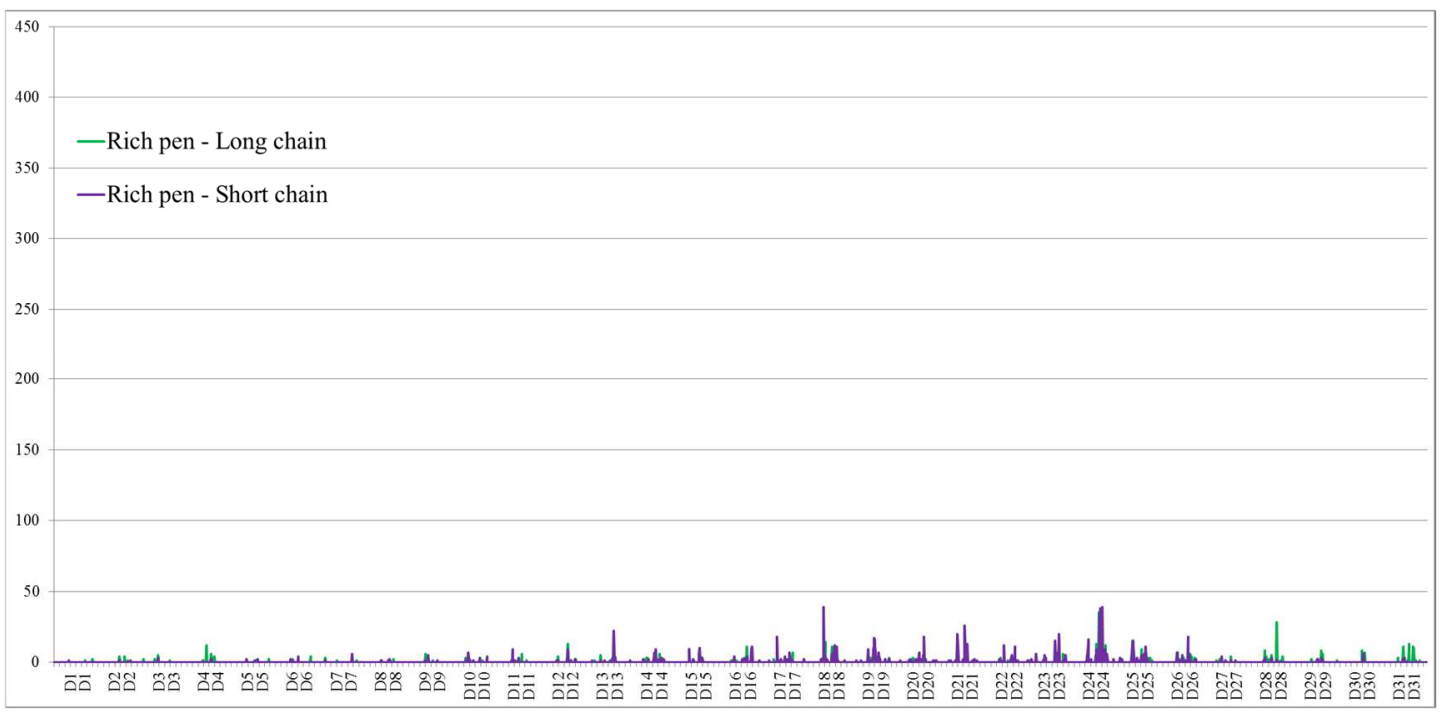

Figure 6.6b Motion Index values over 31 days in the farrowing pen for a short (purple) and somewhat longer (green) metal chain in a rich pen. 


\subsubsection{Conclusion about AMI sensors}

Data obtained from AMI-sensors (motion sensors) attached to hanging enrichment materials may provide valuable supplements to other ways of assessing enrichment value, i.e. expert opinion, RICHPIG assessment, direct (casual/expert) observation and experimental study. AMI-sensors are flexible, can be used on commercial farms, and they are much less expensive and labour intensive than doing a behavioural study. Compared to behavioural observations, AMI data are also more objective (i.e. more related to physics than to the interpretation of an observer). And most importantly, AMI-sensors are able to provide a more comprehensive, minute-by-minute and day-and-night, record of animal-material interactions.

Disadvantages include that AMI-sensors may have a limited sensitivity (e.g. may require a larger number of pens to obtain statistically significant results). AMI sensors can only be attached to certain, esp. hanging, materials, out of reach of the pigs. The sensors need to resist a potentially hostile environment (e.g. moisture, biting, pulling, hitting, ammonia and dust). Furthermore, AMI sensors do not readily allow recording the behavioural elements as is conventional in behavioural studies, and special care must be taken to deal with potentially confounding factors such as different types of object interaction (e.g. manipulation versus touching the object accidentally e.g. during locomotion or pen cleaning). Specific algorithms may be developed to make more fine-grained behavioural distinctions. Also the enrichment materials themselves may affect AMI-sensor data. For example, the sensors themselves may elicit attention from the pigs (esp. when novel) and objects with different physical properties may show different responses to (the same type of) manipulation by the pigs. Hence, the application of AMI-sensors is not as straightforward as it may appear, and further validation is needed before it can be implemented in practice to support the recording of enrichment value. Our AMI-sensor findings, however, seem to confirm existing knowledge (e.g. that a jute sack is used more than a chain; that a chain with ball is used less than a rope). We also found some confirmation of the ability of AMI-sensors to (indirectly) detect contrast in background enrichment (esp. when the contrast is evident). This seems to be in accordance with the hypothesis of communicating vessels. This hypothesis was originally brought to my attention by Johan Zonderland, who also initiated the work on AMI-sensors at Wageningen Livestock Research. Further research is needed to establish in more detail the role of a number of factors (like nutritional status, health, thermal conditions, breed, etc.) on AMI. In this respect, health status may be of particular relevance as AMI-sensors may be useful in early warning of disease and thus help reduce the use of antibiotics. Most importantly, however, given the history of providing inadequate enrichment materials (hockey-type balls, pipe, straw briquette), AMI-sensors may become a valuable supplement to the behavioural observations which are evidently needed to verify RICHPIG-type assessments and other, esp. commercial, claims about enrichment value.

\subsection{What is proper enrichment for intensively farmed pigs in the short term?}

According to the EC Directive, as of 2003 proper investigation and manipulation materials should have been provided to all pigs at all times in all member states. Most European countries have not implemented this in accordance with the scientific communis opinio (Bracke et al., 2007a; Bracke, Submitted). Here I will formulate a proposal meeting this requirement, that is feasible under current commercial conditions and can be implemented widely in the short term. The proposal is based on my own research (RICHPIG, AMI-sensor data), personal observations supplemented with input from colleagues, experts (Bracke, Submitted) and farmers. It is specified in more detail in a supplement, which will be made available online via http://farewelldock.eu and http://hokverrijking.nl. 
Our research indicated that the enrichment value of the short chain can be improved with little extra cost, essentially by making the chain longer, and by adding short pieces of chain, resulting in a branched chain with chain ends both resting on the floor and hanging slightly below nose height of the pigs in any stage of their development. When provided in sufficient quantity, such a branched-chain design is what I recommend as the most suitable starting point (base-line) as well as benchmark (negative control) for (developing) proper enrichment for intensively-farmed pigs. This is especially true when the ratio of enrichment value per invested euro is taken into account. The branched-chain design implies the following conglomerate of specifications in terms of object-design, material, availability and placement:

1: Object-design: A branched chain consists of a vertically-positioned long chain with its end resting on the solid floor over a distance of $20 \mathrm{~cm}$. Two or three additional chain ends (branches) end at or slightly below the nose height of the smallest and middle-sized pigs reared in the pen.

This should allow pigs of all sizes to interact relatively readily with the chain ends. It also allows two or three pigs to play with the chain in the same location, thus supporting social facilitation and synchronisation. Pigs will interact with the chain in both a standing, sitting and lying position, and, most importantly, pigs can stand with their head down manipulating the end of the chain that is lying on the floor with their nose. This resembles (some rudimentary) rooting behaviour.

2: Material: The chains are stainless-steel anchor chains (for at least the last 5-10 links of each chain end). Recommended dimensions are $7 \mathrm{~mm}$ for growing-fattening pigs, 5-6 mm for weaners, 4-5 $\mathrm{mm}$ for piglets and $8 \mathrm{~mm}$ for sows.

Anchor chains have links which are more round and heavier than the cheaper, more ovalshaped c-chains. The links of an anchor chain appear to be more pleasant for the pigs to be held in their mouths, but this is a subjective impression that remains to be confirmed. The size of the links should fit the size of the pigs' oral cavity. Note that the indicated sizes refer to the diameter of the metal, not the diameter of the links. For example, a $7 \mathrm{~mm}$ anchor chain for finishers has links measuring 36x23 mm. For rearing pens (containing growing-finishing pigs ranging in body size from about 25 to $120 \mathrm{~kg}$ ) various chain sizes should be provided in the pen, such that the most preferred types are available for all sizes of pig. Stainless-steel anchor chains are more expensive than c-chains. However, they also last much longer. According to the farmer who recommended the chain link sizes, the stainless-steel anchor chains themselves will last 'forever'. Only the last 5 or so links need to be replaced every 5 - 10 years. This implies that the overall costs of the stainless-steel anchor chains remain very low, esp. when second-hand chains are used. Note that the branched chain is itself equivalent to several chains hanging side by side, except that the shorter 'branches' require less material, and thus costs, to produce chain ends valued by the pigs.

3: Availability and placement: One branched chain is provided for every 5 pigs. The chains are spaced apart as much as possible, preferably with at least one pig length between 2 branched chains in a pig pen. The branched chains are attached at the top end of the pen wall, over the solid floor, and not in the dunging area.

Chains should have some action radius and be accessible to the pigs, even when one chain accidentally gets blocked by a dominant or resting conspecific. So, chains in corners should be avoided, unless they are provided in surplus. Also, when the chains are getting out of reach (e.g. thrown out of the pen), alternative attachment, such as hanging them away from the pen wall, may be required. Chains hanging on the pen wall away from the corner are generally readily accessible without inducing frustration, i.e. the pigs voluntarily approach to interact with them. 


\subsubsection{Are branched chains really proper enrichment?}

No, they are not. But they seem to be almost proper, and they are a major step forward, also according to an international group of pig welfare experts (Bracke, Submitted). Furthermore, farmers should be able to make the last step towards proper enrichment by themselves (Table 6.2). It may only be a small step. For example, perhaps an indestructible object (which is already present in many pig pens, e.g. a ball, pipe or wood) can be added to one of the branched chains. This may well be sufficient to surpass the threshold of both scientific and current legal acceptability. However, it will probably not be enough to reduce the need for tail docking (which is also required by EU law). For this, destructible materials are probably needed. To my knowledge, however, no such materials can be recommended for widespread implementation in intensive pig farming in the short term, unless they are enforced. They are (perceived as too) costly even though they may cost as little as 6-13 eurocents per kg of pig meat (carcass weight) (Zonderland, 2007; Zonderland et al., 2008). Furthermore, the materials may block the manure system and keeping up maintenance is a real challenge. As a consequence, the use of destructible materials on commercial farms tends to be mitigated by practical considerations, often leading to compromised pig welfare benefits. Therefore, it is highly recommended that their enrichment value is verified, e.g. using the branched-chain design in a sufficient number of pens (e.g. 10 pens) as a benchmark.

Table 6.2 Tentative scoring of enrichment materials for intensively farmed pigs in relation to observations reported in the text.

\begin{tabular}{|c|c|}
\hline Score & Enrichment material \\
\hline 10 & Ideal enrichment \\
\hline \multirow[t]{2}{*}{$>=7.0$} & $\begin{array}{l}\text { Destructible materials provided properly, e.g. Forest soil, roughage, fodder } \\
\text { beet, maize silage, grass (silage), whole straw with chopped beet roots, with } \\
\text { maize silage or with additional feed, a bale of straw, long straw with fir } \\
\text { branches and straw with forest bark and branches (all median expert scores } \\
>=7.0 \text { ) } \\
\text { Plenty of long straw on the floor, regularly renewed } \\
\text { Compost from a dispenser, straw pellets (loose or from a plastic dispenser) } \\
\text { and straw in a metal basket; ropes, jute, soft wood, substrates }\end{array}$ \\
\hline & Branched chain + indestructible objects \\
\hline \multirow[t]{4}{*}{5.5} & $\begin{array}{l}\text { Cut-off of what is minimally acceptable or 'proper enrichment' (above this } \\
\text { line) }\end{array}$ \\
\hline & Branched chain design \\
\hline & Short chain \\
\hline & $\begin{array}{l}\text { Destructible materials provided improperly (e.g. limited access/not } \\
\text { destructible/soiled), e.g. Straw briquette; narrow hay rack; forced grass } \\
\text { silage consumption; large, swinging softwood; loose logs, rope-and-rubber, } \\
\text { wooden plank }\end{array}$ \\
\hline
\end{tabular}

Short chain with indestructible ball/pipe

$<2.5$ A mirror, a concrete block, a rubber mat, a minimal amount of straw (!), a mineral block, a heavy plastic ball (on the floor), a chain (with or without hard wood attached to it), a rubber-hose cross, a free toy (sow neck tether), a hanging car tyre, a bucket, an additional operant feeder, a fixed wood block, bite rite (i.e. a plastic cone with 'tail-like' projections), and a knotted rope (all median expert scores $<2.5$ ) 
In my view branched chains provide by far the most feasible solution for short-term pig enrichment. Many aspects of their design as well as prospects for further improvement still remain to be verified and falsified in further research. However, in answering the question 'what is proper pig enrichment in the short term', it is better to avoid suggesting that more research is needed, at least in the classical sense of scientists working in research laboratories/research stations. Because further research could (again) lead to delays in implementation of the knowledge which is available at present.

Before the EC Directive was implemented in the Netherlands, a metal chain was considered proper enrichment. This was often a short chain, reaching not further than nose height. Such a chain would seem highly feasible, involving low cost and hardly any labour, totalling 0.25 euro per pig per year (Zonderland, 2007). Nevertheless, farmers were reluctant to provide it as almost 10 years after prior legislation coming into force in 1994 (Anonymous, 1994), the government was still urged to enforce it (Bleijenberg, 2003). Currently, providing the legally required enrichment (i.e. adding an indestructible piece of pipe or ball to the metal chain) has been an issue until recently in the Netherlands (NVWA, 2015a; 2015b) as well as in most other European countries (CIWF, 2013; 2014). In non-European countries, like the US, Canada and New Zealand, most pig farmers don't provide any enrichment, apparently because it is not (considered to be) cost-effective (Bracke, Submitted).

However, from a legal perspective, there is increasing pressure to improve pig enrichment. Recent EC guidelines (EC, 2016; 2016b) recommend that destructible materials should be provided. However, the new guidelines are neither legally binding, nor specified in much detail. Chains are classified as 'materials of marginal interest', which cannot be provided alone. Other marginal materials include "rubber, soft plastic pipes, hard plastic, hard wood, ball, salt lick" (EC, 2016). The new minimum recommendation appears to be to provide either a marginal material like a chain together with a so-called 'suboptimal material', or two suboptimal materials. Suboptimal materials include straw, hay, or silage in a rack/dispenser, soft wood, natural rope and hessian sack, but also natural soft rubber, sawdust, sawdust briquette, compressed straw in a cylinder (i.e. straw briquette), pellet dispenser and 'sand and stones'. The guidelines have open standards on various materials, e.g. what classifies as soft wood, how accessible the straw provided in straw racks or straw briquettes must be, and what dimensions of wood would be acceptable (as e.g. large logs of softwood can be indestructible and thus ineffective for the pigs). Also, rubber is classified in the guidelines as marginal, but natural rubber is suboptimal. Natural rubber is frequently used in materials like car tyres, and the guidelines do not specify how soft 'soft natural rubber' must be. Because the guidelines have open (i.e. unspecified) standards, implementation will be difficult and the overall effect on pig welfare will differ between farmers. When pig farmers try to (or are forced to) reduce costs, they may (try to) provide a stone and a chain, for example, or a straw briquette as described in the Directive and practiced in some welfare schemes in a suboptimal way (as described earlier in this chapter). Such 'enrichments' may have a very limited actual welfare benefit, especially when compared to providing the full branched-chain design (see the supplement for more details).

Our on-farm observations also point in this direction. Conventional pigs provided with limited access to a hay rack or a soft-wood beam showed signs of frustration, enhanced aggression and skin lesions, as (conversely) did organic pigs that were fed substantial amounts of grass silage (Bikker and Binnendijk, 2012; Wind et al., 2012). Furthermore, weaners provided simultaneously with a bundle of chains hanging till floor level, a (rather big but soft) wooden plank, a rope and a flexible rubber toy (piece of hanging rubber mat), interacted about three times more with the chains than with the other materials. Also, fattening pigs simultaneously 
provided with a short chain and a rope with a flexible rubber flap interacted more often with the chain than with the rope-and-rubber. The rope-and-rubber was virtually indestructible, whereas the chain was a 'proper' stainless steel anchor chain reaching about $20 \mathrm{~cm}$ closer to the floor than the rope-and-rubber (52 and $33 \mathrm{~cm}$ respectively) (Ettema, 2010a). In these examples, the suggestion in the new guidelines that chains are inferior to the other materials, i.e. wood-rope and rope-rubber combinations, appears to be false. If so, allowing the combination of materials while rejecting the chains, seems to be suboptimal as regards pig welfare as well as suboptimal as regards the economic interests of farmers and consumers. Economic considerations alone may justify the use of branched chains, as no alternative material seems to provide as much welfare improvement for every Euro invested in enrichment. Furthermore, indirect economic benefits may include improving pig health by reducing stress and the use of antibiotics, or perhaps by reducing the cost of tail biting (which occurs in intensive pig farming despite tail docking, Zonderland et al. (2011)). But such indirect economic benefits, however, remain to be shown.

Non-economic considerations also need to be taken into account. This includes pig welfare in intensive pig farming systems, with proper enrichment being a notable item for pig welfare. The branched-chain design provides a unique opportunity for the pig sector. It can lead to proper pig enrichment and intact tails, two increasingly recognised requirements necessary to maintain a societal licence to produce. Within animal welfare, pig enrichment is special, because of its association with positive welfare, rather than with reducing suffering (as in the case of reducing tail docking, for example). Enrichment materials are very much visible to visitors and provide an opportunity to explain about pig welfare and how the pig sector is responding to societal concerns. In this way, enrichment may become the pig sector's flagship of the transition towards a better future, a future also where former enemies perhaps may become allies (see supplement). The final section explains how this may happen.

\subsection{Intelligent Natural Design}

Intelligent Natural Design (IND) holds the promise of resolving persistent welfare problems by organising an evolutionary process resembling natural selection, e.g. by providing economic incentives to promote desirable outcomes. IND is a term coined to solve complex pig-welfare problems, like proper enrichment and intact tails, through human-made evolution (Bracke, 2010; Bracke et al., 2011). The concept derives from a so-called TED talk entitled 'Trial, error and the God complex' (Harford, 2011). Harford explains how Unilever physicists failed to design a properly-functioning nozzle to make washing powder. The problem was finally solved by an evolutionary biologist, Steve Jones, who subjected the problem to a process of human-made evolution. Jones built 10 different nozzles as a first 'generation', selected the best ones, and repeated this trial-and-error selection process for 45 'generations'. It resulted in a nozzle that performed much better than the solutions scientists had been able to come up with. Harford suggests this approach can solve just about any problem. I propose it can solve the problem of providing proper pig enrichment as well. Yet, I also think the method needs refinement, because a fully 'blind' trial and error process applied to pig welfare could lead to poor welfare, putting it at risk of being unethical. Also, being a welfare scientist myself, I believe available knowledge should be used intelligently. Hence, IND expresses the ambition of an 'intelligent' evolution. IND combines the phrases 'intelligent design' and 'natural'. Natural is what happens in nature, i.e. evolution guided by natural selection. It has an impressive ability to find the most elegant solutions for very complex design problems through trial and error, i.e. without relying on scientific knowledge or intelligence. 'Intelligent design' normally refers to a religious form of creationism holding the view that certain features of the universe and of living things are best explained by an intelligent cause (Wikipedia, 2016). 'Intelligent design' in IND, however, refers to the idea that we may 
intelligently design the conditions needed to facilitate gradual, evolution-like improvements towards more desirable and sustainable livestock-production systems. For this scientific understanding of underlying mechanisms is desirable, but not absolutely necessary. We should use it, where possible.

According to the principle of IND, we may organise individual variation and persistent selection to deal with pig enrichment. For this, the main selection criterion is pig occupation, i.e. the time spent in voluntary, enrichment-directed behaviour or AMI. AMI duration and the type of AMI may be recorded using behavioural observations and using AMI-sensors. Pig tails provide a related selection criterion. Pig tails may be measured in terms of tail lesions and tail length. Using these criteria the selection process starts with comparing the most promising feasible enrichment materials. As a starting point, this should include the branchedchain design as described above. The enrichments are implemented in a limited number of pens ('individuals'). Enrichment materials, or combinations of materials, in pens are then compared, either as individuals or as a group of 'clones'/treatments, to see which is doing best in terms of providing pig occupation. The best, most 'fit', 'individuals'/enrichments are selected and used to 'generate', i.e. design and install, the next 'generation' in, say, a new batch of pigs. When repeated persistently, this process should inevitably lead to gradually improved enrichment. Ideally, the selection process should lead to considerably improved pig welfare. This requires the ample performance of positive, natural behaviours (Bracke and Hopster, 2006; Bracke and Spoolder, 2011b) and a minimised level of abnormal behaviours, mutilations and health problems.

Farmers should be responsible for the implementation of the branched chains on their farms, and for the IND selection process and innovation. This turns farmers into a kind of pioneers for doing participative science. It implies that farmers themselves, alone or with the help of others (e.g. vets, students, scientists), make science-based comparisons. As a result, supplementing a comparison of individual instances of enrichment materials as in the case of the nozzles for making washing powder, IND proposes comparing groups/repetitions/'clones' of enrichment treatments as much as possible in accordance with scientific standards (e.g. random allocation of enrichment treatments; standardised observations, statistical analysis, etc.). This makes sense, i.e. is smart, because pig enrichment is subject to considerable individual variation (Feddes and Fraser, 1994), as is the case in nature (and much less so in washing-powder nozzles). It is also smart because intensive pig farms typically have many repetitions of highly similar pig pens. This allows repetitions/'clones' of enrichment treatments to be compared at a group level, i.e. as average value and standard deviation, in addition to making a comparison at individual level. Not all farmers would have the time and skills required to do such science-based comparisons themselves. But, firstly, it is not necessary for IND to work, and, secondly, many farmers would have the skills to make it possible, e.g. through (scientifically-trained) extension and by allowing students and scientists do the work on their farm.

Main challenges include overcoming economic constraints, and re-directing farm management from its primary focus on maximised production efficiency to focussing on maximised efficiency of inclusive welfare. This includes both farmer welfare, of which economy is a most important component, and animal welfare. Seeking maximised overall welfare implies recognising that feasibility is a necessary condition. As such branched chains are feasible, and destructible materials generally are not (or not yet). It also implies that the impressive capacities of the pig sector to innovate for economic reasons can be redirected such that existing skills could innovate for improved animal welfare too. Innovating for personal financial gain often involves keeping knowledge private, because its leading principle is individual selection. By contrast, IND would promote altruism via group selection, thus suggesting that farmers share information, e.g. about which enrichments are 
promising and which are not. In this way the wheel doesn't have to be invented time and time again. Sharing also facilitates correction of potentially biased or misleading claims.

IND acknowledges that modern intensive pig production is itself the product of human-made selection, in particular of economic selection for maximised production efficiency. This implies that IND-based solutions for enrichment should work with, rather than oppose the underlying economic forces. Current economic forces are pulling towards completely barren pens, as is practiced in most countries outside the EU. Legislative measures and welfare schemes try to counteract this. For IND to succeed, it is important to start pushing towards welfare improvements. This implies providing incentives for doing well, and imposing a (relative) material or immaterial cost on doing less well. Several examples may illustrate how different stakeholders can implement IND by creating economic and other incentives to promote innovation towards more proper pig enrichment.

The first example is for regulatory bodies to use existing EU legislation to stimulate pigwelfare improvement. In particular, current EU legislation (EC, 2001) contains articles banning routine tail docking and teeth treatment at an older age. In particular, it also prescribes that 'plentiful straw' must be provided in cases of 'severe fighting' 'which goes beyond normal behaviour' (Article 3 of the Annex). Enforcing these requirements could promote better enrichment directly, e.g. by providing plenty of straw in case of tail biting (which was more commonly regarded as a form of abnormal fighting behaviour in the early days of drafting animal welfare legislation; and to some extent it may well be (e.g. when it originates at the feeder), even though ethologists now commonly agree that tail biting is not an agonistic behaviour as such). Enforcing existing legislation could also promote better enrichment indirectly, e.g. by requiring more serious efforts to stop tail docking.

A second example is more directed towards other chain actors and towards reward rather than punishment. Slaughterhouses could put a premium on pigs with longer and intact tails, at very little or no costs to themselves. The premium may be financed in various ways, e.g. through a general check-off payment by the farmers. This would imply a redistribution of (some) money from the worse to the better farmers. It may also be paid for by consumers, retailers and governments who feel this is important for sustainability. Also crowd-funding and prizecontests could be organised to generated incentives for farmers to implement the branchedchain design, and start directing innovation towards better animal welfare, proper enrichment and intact, curly pig tails in intensive pig farming (see also the supplement).

A welfare scheme is also conceivable where consumers can pay directly for improved enrichment, much in the way they can already pay for green energy and for climate-neutral holiday flights. In this way welfare revenue can go more directly (via the farmers) to the pigs rather than to the intermediate actors in the supply chain as tends to happen in most current welfare schemes. In fact, the top-end of enrichment, i.e. providing a sufficient amount of straw to stop routine tail docking and to raise pigs with intact curly tails on well-managed pig farms, may cost perhaps as little as about 5 (to perhaps 10) euro per pig, i.e. 6-13 eurocents per kg of pig meat (carcass weight) (Zonderland, 2007; Zonderland et al., 2008). If consumers would be willing to donate this kind of money to pig farmers, tail docking could soon come to an end. I even believe that the RICHPIG model (Bracke et al., 2007a; Bracke, 2008) and the more recent expert scores (Bracke, Submitted) provide a fairly sound basis for the suggestion that branched chains and the IND approach could be turned into one of the most cost-effective charitable objectives available at present to tangibly improve (any kind of) animal welfare (cf Effective Altruism, Wikipedia (2016b); (Singer, 2015)). (More ideas on IND and the development of proper pig enrichment are described in the supplement at http://www.farewelldock.eu/.) 


\section{Acknowledgements}

I would like to thank: the ANIWHA Era-Net initiative, FareWellDock project and partners (See www.farewelldock.eu), the Dutch Ministry of Economic Affairs, ICCOP (CORE

ORGANIC II), H. Vermeer, A. Aarnink, M. Verhoeven, M. Gerritzen, A. de Greef, H. Smith et al., I. v Dixhoorn, K. Ettema, S. Wind, J. Zonderland, M. Kluivers, S. Edwards, A. Valros, A. Rebel, M. Spinka, Elsevier, pig farmers \& pigs.

\section{References}

Anonymous, 1994. Varkensbesluit [Dutch Pig Directive].

Anonymous, 2001. Scientists' Assessment of the Impact of Housing and Management on Animal Welfare. Journal of Applied Animal Welfare Science 4, 3-52.

Anonymous, 2012b. Angry Birds? No Happy Pigs. Science 335, 19.

Bijma, P., Muir, W.M., Ellen, E.D., Wolf, J.B., Van Arendonk, J.A., 2007b. Multilevel selection 2: estimating the genetic parameters determining inheritance and response to selection. Genetics 175, 289-299.

Bijma, P., Muir, W.M., Van Arendonk, J.A., 2007a. Multilevel selection 1: quantitative genetics of inheritance and response to selection. Genetics 175, 277-288.

Bikker, P., Binnendijk, G., 2012. Ingekuild gras voor biologisch gehouden vleesvarkens. [Grass silage for organic fattening pigs]. Report 603. Available: http://edepot.wur.nl/166598. Accessed 11-5-2016, Wageningen UR Livestock Research, Lelystad, The Netherlands.

Bleijenberg, M., 2003. Ministerie van LNV houdt openbare stukken achter [Ministry of LNV is witholding public documents].

Bodin, L., Algers, B., Andersson, M., Olsson, A., Botermans, J., 2015. The Amount of Straw for Growing-Finishing Pigs Considering the Reduction of Time Spent in Manipulative Behavior. SOJ Veterinary Sciences 1, 1-6.

Bracke, M., Aarnink, A., Vermeer, H.M., 2014. Extra snijmais goed voor welzijn varkens. [Extra maize silage good for pig welfare]. Available: http://edepot.wur.nl/323897 Accessed 17-2-2015. V-focus, 34-35.

Bracke, M., De Lauwere, C.C., Wind, S.M., Zonerland, J.J., 2013. Attitudes of Dutch pig farmers towards tail biting and tail docking. J Agric Environ Ethics 26, 847-868.

Bracke, M., Hopster, H., 2006. Assessing the Importance of Natural Behavior for Animal Welfare. J Agric Environ Ethics 19, 77-89.

Bracke, M., Spoolder, H., 2011b. Review of wallowing in pigs: implications for animal welfare. Animal Welfare 20, 347-363.

Bracke, M.B.M., 2006. Expert opinion regarding environmental enrichment materials for pigs. Animal Welfare 15, 67-70.

Bracke, M.B.M., 2007b. Multifactorial testing of enrichment criteria: Pigs 'demand' hygiene and destructibility more than sound. Applied Animal Behaviour Science 107, 218-232.

Bracke, M.B.M., 2008. Richpig: a semantic model to assess enrichment materials for pigs. Animal Welfare 17, 289-7286.

Bracke, M.B.M., 2009. Rope test may indicate efficacy of tail-biting treatments in growing pigs. Animal Welfare 18, 263-7286.

Bracke, M.B.M., 2010. Towards long(er) pig tails: New strategy to solve animal welfare problems, In: Lidfors, L., Blokhuis, H., Keeling, L. (Eds.), Proceedings of the 44th Congress of the ISAE, August 4-7 2010, Wageningen Academic Publishers, Uppsala, Sweden, p. 135.

Bracke, M.B.M., 2010b. Afleidingsmateriaal initiatief. [Enrichment materials initiative]. Unpublished email to main representatives of the pig sector. Sept. 4, 2010. Wageningen Livestock Research. 
Bracke, M.B.M., 2011c. Prijsvraag. [Prize contest]. Available: http://hokverrijking.nl/prijsvraag/.

Bracke, M.B.M., 2011d. European legislation on enrichment fails to improve pig welfare (unpublished manuscript). Wageningen Livestock Research.

Bracke, M.B.M., 2016a. Interaction of suckling and weaned piglets with long and short play chains while housed in barren and enriched pens (and exploratory infection with APP) (unpublished). Wageningen Livestock Research.

Bracke, M.B.M., 2016b. Accelerometer on play chain may detect pigs' responses to major stressors such as experimental Streptococcus infection (unpublished). Wageningen Livestock Research.

Bracke, M.B.M., 2017. Chains as proper enrichment for intensively-farmed pigs?, in: Spinka, M. (Ed.), Advances in Pig Welfare, Elsevier.

Bracke, M.B.M., Submitted. Expert opinion on metal chains and other indestructible objects as proper enrichment for intensively-farmed pigs.

Bracke, M.B.M., Ettema, K., 2014. Pigs suffering from injurious behaviours like flank biting and tail biting are more interested to manipulate a novel rope than uninjured control animals. Available:

http://www.measuringbehavior.org/files/2014/Proceedings/Bracke,\%20M.B.M.;\%20Ette ma,\%20K.\%20-\%20MB2014.pdf/. Accessed 28-8-2014, In: Spink, A.J., Loijens, L.W.S., Woloszynowska-Fraser, M., Noldus, L.P.J.J. (Eds.), Proceedings of Measuring Behavior August 27-29 2014, Wageningen, The Netherlands, pp. 280-284.

Bracke, M.B.M., Hulsegge, B., Keeling, L., Blokhuis, H.J., 2004a. Decision support system with semantic model to assess the risk of tail biting in pigs: 1. Modelling. Applied Animal Behaviour Science 87, 31-44.

Bracke, M.B.M., Spoolder, H.A.M., 2007b. Novel object test can detect marginal differences in environmental enrichment in pigs. Applied Animal Behaviour Science 109, 39-48.

Bracke, M.B.M., Vermeer, H., Bokma, M., Van der Peet, C., Bolhuis, L., Leeijen, J., 2012. Checklist aanpak staartbijten bij (biologische) varkens. [Checklist dealing with tail biting in (organic) pigs] Flyer. Available: http://edepot.wur.nl/220045. Accessed 11-5-2016, Wageningen Livestock Research, Lelystad.

Bracke, M.B.M., Vermeer, H.M., Aarnink, A.J.A., 2015 (unpublished). Effects of maize silage and secondary variables like gender and room temperature on pig behaviour and welfare, and the use of data loggers recording toy manipulation (report). Wageningen Livestock Research.

Bracke, M.B.M., Wolthuis, M., Zonderland, J.J., Kluivers, M., 2011. Tails to tell - Tail docking, tail biting and enrichment for pigs - Experiences from the Netherlands. Available:

http://vsp.lf.dk/ /media/Files/Temagruppemode/Management $\% 20$ slagtesvin/Bracke $\% 20 t i 1$ gang\%20til\%20halebidsproblematikken\%20i\%20holland.ashx. Accessed 10-5-2016, Herning, Denmark, May 25-26, 2011.

Bracke, M.B.M., Zonderland, J.J., Bleumer, E.J.B., 2007a. Expert judgement on enrichment materials for pigs validates preliminary RICHPIG model. Applied Animal Behaviour Science 104, 1-13.

Bracke, M.B.M., Zonderland, J.J., Bleumer, E.J.B., 2007b. Expert consultation on weighting factors of criteria for assessing environmental enrichment materials for pigs. Applied Animal Behaviour Science 104, 14-23.

Bracke, M.B.M., Zonderland, J.J., Lenskens, P., Schouten, W.G.P., Vermeer, H., Spoolder, H.A.M., Hendriks, H.J.M., Hopster, H., 2006. Formalised review of environmental enrichment for pigs in relation to political decision making. Applied Animal Behaviour Science 98, 165-182. 
CBS, 2011. Landbouw, gewassen, dieren en grondgebruik naar regio (Agriculture, crops, animals and soil use by region). Centraal Bureau voor de Statistiek (Statistics Netherlands). Available at http://statline.cbs.nl/StatWeb/publication/?DM=SLNL\&PA=80780NED\&D1=500$517,538,542,550 \& \mathrm{D} 2=0 \& \mathrm{D} 3=0,5,(1-2),(1-1), 1 \& \mathrm{HDR}=\mathrm{G} 1, \mathrm{G} 2 \& \mathrm{STB}=\mathrm{T} \& \mathrm{VW}=\mathrm{T}$.

CIWF, 2008. The state of Europe's pigs: an exposé. Available: http://www.ciwf.org.uk/includes/documents/cm_docs/2008/s/state_of_europes_pigs_2008 _uk.pdf. Accessed 25-01-2010, Compasion in World Farming, Goldaming, Surrey, UK.

CIWF, 2013. Reports by the Food and Veterinary Office that show failure to enforce provisions of Council Directive 2008/120/EC on the protection of pigs that require enrichment materials to be provided and that ban routine tail docking. Available: http://www.ciwf.org.uk/includes/documents/cm_docs/2013/f/fvo_reports_on_failure_to_e nforce_pigs_directive_compiled_by_compassion_in_world_farming_sept_2013.pdf. Accessed 20-1-2016, Compassion in World Farming, River Court, Surrey, UK.

CIWF, 2014. Lack of compliance with the Pigs Directive continues: Urgent need for change. Available: https://www.ciwf.org.uk/media/5508030/lack-of-compliance-with-the-pigsdirective-continues-urgent-need-for-change.pdf. Accessed 25-8-2016, Compassion in World Farming.

Courboulay, V., 2006. Intérêts comparés d'un objet fixé au sol ou d'un apport de paille comme matériaux d'enrichissement du milieu de vie pour le porc à l'engrais (Impact of straw provision or of a ground fixed object as environmental enrichments for growingfinishing pigs). . J. Rech. Porcine 38, 421-426.

Courboulay, V., 2011. Utilisation de différentes modalités de mise à disposition de chaînes pour des porcs en engraissement: impact sur le comportement et les lésions des animaux. [Chain-based objects used as enrichment toys: Effects on behavior and lesions in fattening pigs]. Available: http://www.cabi.org/cabdirect/FullTextPDF/2012/20123233837.pdf. Accessed 25-2-2016. Journées de la Recherche Porcine en France 43, 183-184.

De Grau, A.F., Dewey, C., E., Widowski, T., M., Friendship, R., M. , De Lange, C.F., Milligana, B., 2005. Reducing Weight Variation and Behaviour Problems in Nursery Pigs on a Commercial Farm by Improving Water Accessibility and Providing Environmental Enrichment. Journal of Animal and Veterinary Advances 4, 51-57.

de Greef, K.H., Vermeer, H.M., Houwers, H.W.J., Bos, A.P., 2011. Proof of Principle of the Comfort Class concept in pigs.: Experimenting in the midst of a stakeholder process on pig welfare. Livestock Science 139, 172-185.

de Greeff, A., van Selm, S., Buys, H., Harders-Westerveen, J.F., Tunjungputri, R.N., de Mast, Q., van der Ven, A.J., Stockhofe-Zurwieden, N., de Jonge, M.I., Smith, H.E., 2016.

Pneumococcal colonization and invasive disease studied in a porcine model. BMC microbiology 16, 1-8.

De Lauwere, C., Hoogendam, K., Zonderland, J., Bracke, M., 2009. Stoppen met couperen? Varkenshouders over staartbijten en staartcouperen. [Stoppnig tail docking? Pig farmers on tail biting and tail docking]. LEI report 2009-97. Available: https://www.wageningenur.nl/nl/Expertises-

Dienstverlening/Onderzoeksinstituten/livestockresearch/show.htm?publicationId=publication-way-333838303639. Accessed 1-5-2016, LEI, The Hague, p. 60.

EC, 2001. Commission Directive 2001/93/EC of 9 November 2001 amending Directive 91/630/EEC laying down minimum standards for the protection of pigs. Official Journal of the European Communities. Available: http://eur-lex.europa.eu/legalcontent/EN/ALL/?uri=CELEX\%3A32001L0093. Accessed 4-5-2016. 
EC, 2014. Guidelines on the provision of enrichment material for pigs. Brussels. Available: http://ec.europa.eu/dgs/health_foodsafety/information_sources/docs/ahw/20140701_guideline_enrichment_en.pdf. Accessed 8-1-2016.

EC, 2016. Commission staff working document on best practices with a view to the prevention of routine tail-docking and the provision of enrichment materials to pigs Accompanying the document Commission recommendation on the application of Council Directive 2008/120/EC laying down minimum standards for the protection of pigs as regards measures to reduce the need for tail-docking. Available: http://ec.europa.eu/food/animals/docs/aw-pract-farm-pigs-staff-working-document_en.pdf. Accessed 15-3-2016.

EC, 2016b. Commission recommedation (EU) 2016/336 of 8 March 2016 on the application of Council Directive 2008/120/EC laying down minimum standards for the protection of pigs as regards measures to reduce the need for tail-docking. March 8, 2016. Available: http://eur-lex.europa.eu/legalcontent/EN/TXT/?uri=uriserv:OJ.L_.2016.062.01.0020.01.ENG\&toc=OJ:L:2016:062:TO C. Accessed 23-3-2016.

EC, 2016c. Final report of a study visit carried out in Sweden from 23 February 2016 to 26 Februari 2016 in order to share best practice on rearing pigs with intact tails. DG Sante. Brussels. Available: http://ec.europa.eu/food/auditsanalysis/audit_reports/details.cfm?rep_id=3645. Accessed 5-8-2016.

EFSA, 2007a. Animal health and welfare in fattening pigs in relation to housing and husbandry. Available: http://www.efsa.europa.eu/sites/default/files/scientific_output/files/main_documents/564.p df. Accessed 10-5-2016, EFSA, Parma, Italy.

$\mathrm{EFSA}, 2007 \mathrm{~b}$. The risks associated with tail biting in pigs and possible means to reduce the need for tail docking considering the different housing and husbandry systems. Available: http://www.efsa.europa.eu/en/efsajournal/doc/611.pdf. Accessed 10-5-2016, EFSA, Parma, Italy.

EFSA, 2014. Scientific Opinion concerning a multifactorial approach on the use of animal and non-animal-based measures to assess the welfare of pigs. EFSA Journal 12(5): 3702. Available:

http://www.efsa.europa.eu/sites/default/files/scientific_output/files/main_documents/3702. pdf. Accessed 07-01-2016.

EMA, 2016. European Surveillance of Veterinary Antimicrobial Consumption (ESVAC). Available:

http://www.ema.europa.eu/ema/index.jsp?curl=pages/regulation/document_listing/docume nt_listing_000302.jsp. Accessed 25-8-2016.

Ettema, K.C., 2010a. Prevention of tail biting behaviour through increased welfare. Student thesis Van Hall Larestein.

Ettema, K.C., 2010b. The underestimated value of the chain as a toy for pigs (unpublished information sheet). Van Hall-Larestein/Wageningen Livestock Research.

Feddes, J., Fraser, D., 1994. Non-nutritive chewing by pigs: implications for tail-biting and behavioral enrichment. Transactions of the ASAE 37, 947-950.

Fraser, D., 1987a. Mineral-deficient diets and the pig's attraction to blood: implications for tail-biting. Canadian Journal of Animal Science 67, 909-918.

Grandin, T., 1989. Effect of rearing environment and environmental enrichment on behavior and neural development in young pigs. Available:

https://www.ideals.illinois.edu/handle/2142/21967. Accessed 14-5-2016, University of Illinois at Urbana-Champaign. 
Harford, T., 2011. Trial, error and the God complex. Available:

http://www.ted.com/talks/tim_harford\#t-657729. Accessed 28-6-2016, TED talk.

Herskin, M.S., Jensen, H.E., Jespersen, A., Forkman, B., Jensen, M.B., Canibe, N., Pedersen, L.J., 2015. Impact of the amount of straw provided to pigs kept in intensive production conditions on the occurrence and severity of gastric ulceration at slaughter. Research in Veterinary Science.

HKU, 2011. Playing with Pigs: Pig Chase. Available: https://vimeo.com/29046176. Accessed 25-8-2016.

Horrell, R., A'Ness, P., Edwards, S., Eddison, J., 2001. The use of nose-rings in pigs: consequences for rooting, other functional activities, and welfare. Animal Welfare 10, 322.

LNV, 2007. Goede afleiding voor uw varkens. [Good distraction for your pigs]. Brochure. Available: https://www.rijksoverheid.nl/documenten/brochures/2007/05/16/goedeafleiding-voor-uw-varkens. Accessed 1-5-2016.

Muir, W.M., 2003. Indirect selection for improvement of animal well-being., pp. 247-256 in Poultry Genetics Breeding and Biotechnology, edited by W. M. Muir and S. Aggrey. CABI Press, Cambridge, MA.

Munsterhjelm, C., Peltoniemi, O.A., Heinonen, M., Hälli, O., Karhapää, M., Valros, A., 2009. Experience of moderate bedding affects behaviour of growing pigs. Applied Animal Behaviour Science 118, 42-53.

NVWA, 2015a. Varkens - Naleving welzijnsregels bij varkenshouders van $60 \%$ naar $74 \%$. [Pigs - Compliance animal welfare regulations among pig farmers from $60^{\wedge}$ to $74 \%$ ]. Available: https://www.nvwa.nl/onderwerpen/dieren-dierlijkeproducten/dossier/varkens/nieuwsoverzicht/nieuwsbericht/2064241/nalevingwelzijnsregels-bij-varkenshouders-van-60-naar-74. Accessed 5-5-2016.

NVWA, 2015b. MANCP Meerjarig National ControlPlan Nederland. Jaarverslag 2014. [MANCIP More-year control plan Netherlands. Year report 2014]. Available: https://www.nvwa.nl/actueel/bestanden/bestand/2209042/mancp-meerjarig-nationaalcontroleplan-nederland-2014. Accessed 27-6-2016, NVWA, The Hague.

Parmentier, L., 2007. Speelgoed voor varkens. [Toys for pigs], KU Leuven, Leuven.

Pedersen, L.J., Herskin, M.S., Forkman, B., Halekoh, U., Kristensen, K.M., Jensen, M.B., 2014. How much is enough? The amount of straw necessary to satisfy pigs' need to perform exploratory behaviour. Applied Animal Behaviour Science 160, 46-55.

Schouten, W., Wiegant, V., 1996. Individual responses to acute and chronic stress in pigs. Acta physiologica scandinavica. Supplementum 640, 88-91.

Scott, K., Taylor, L., Gill, B.P., Edwards, S.A., 2007. Influence of different types of environmental enrichment on the behaviour of finishing pigs in two different housing systems: 2. Ratio of pigs to enrichment. Applied Animal Behaviour Science 105, 51-58.

Singer, P., 2015. The most good you can do: How effective altruism is changing ideas about living ethically. Yale University Press, London.

Spoolder, H.A.M., Bracke;, M., Mueller-Graf;, C., (Eds);, S.E., 2011. Scientific report updating the EFSA opinions on the welfare of pigs - Report 2 - Update of animal health and welfare aspects in relation to housing and husbandry of weaned, growing and fattening pigs, including space, floors, tail biting and tail docking - Consisting of 3 subreports corresponding to 3 EFSA's scientific opinions to be updated - 31 May 2011, Available:

http://www.efsa.europa.eu/sites/default/files/scientific_output/files/main_documents/181e. pdf. Accessed 18-3-2016, EFSA, Parma, Italy.

SVC, 1997. The welfare of intensively kept pigs. Report to the Directorate General XXIV of the European Commission. Adopted 30. September 1997. Doc. XXIV/ScVc/0005/97, 
Scientific Veterinary Committee, Animal Welfare Section, Brussels. Available: https://www.google.nl/url?sa=t\&rct=j\&q=\&esrc=s\&source=web\&cd=1\&ved=0ahUKEwj aldy6is_MAhVJK8AKHUC5DogQFggiMAA\&url=http\%3A\%2F\%2Fec.europa.eu\%2Ffo od\%2Fanimals\%2Fdocs\%2Faw_arch_1997_intensively_kept_pigs_en.pdf\&usg=AFQjCN HhxlkkVO_On0rmCmmS2SWbYiRocg\&sig2=AlcloGs_eoFPNGQBIDU-Hg\&cad=rja. Accessed 10-5-2016.

Telkänranta, H., Bracke, M.B.M., Valros, A., 2014a. Fresh wood reduces tail and ear biting and increases exploratory behaviour in finishing pigs. Applied Animal Behaviour Science 161, 51-59.

Ten Have-Mellema, A., Van Gemert, W., 2006. Afleidingsmateriaal bij varkens. [Enrichment materials for pigs]. Letter to the Minister of Agriculture, C. Veerman, from LTO and NVV. Available: http://www.oudewebsite.ltonoord.nl/binaries/10213715_f232055994brief-afleidingsmateriaal.doc. Accessed 5-5-2016.

Ursinus, W., Wijnen, H., Bartels, A., Dijvesteijn, N., van Reenen, C., Bolhuis, J., 2014b. Damaging biting behaviors in intensively kept rearing gilts: The effect of jute sacks and relations with production characteristics. Journal of animal science 92, 5193-5202.

Van de Weerd, H.A., Docking, C.M., Day, J.E., Avery, P.J., Edwards, S.A., 2003. A systematic approach towards developing environmental enrichment for pigs. Applied Animal Behaviour Science 84, 101-118.

Van den Berg, B., 2016. NGO perspectives on developing and implementing a Quality Assurance scheme for improving the rearing of pigs and phasing out tail docking. Available via https://circabc.europa.eu/faces/jsp/extension/wai/navigation/container.jsp (accessed 21-10-2016). Meeting on actions to prevent tailbiting and reduce tail docking of pigs, 4-6 Oct., 2016, Grange, Ireland.

Van Dixhoorn, I.D.E., Reimert, I., Middelkoop, J., Bolhuis, J.E., Wisselink, H.J., Koerkamp, P.W.G.G., Kemp, B., Stockhofe-Zurwieden, N., 2016. Enriched housing reduces disease susceptibility to co-infection with Porcine Reproductive and Respiratory Virus (PRRSV) and Actinobacillus pleuropneumoniae (A. pleuropneumoniae) in young pigs. Available: http://journals.plos.org/plosone/article?id=10.1371/journal.pone.0161832. Accessed 11-92016. PloS one 11, e0161832.

Van Peer, I., 2012. Playing with Pigs: Irene van Peer at TEDxBrussels. TEDx talk. Available: https://www.youtube.com/watch?v=bCHMCRIHTD0. Accessed 25-8-2016.

Varkensloket, 2014. Geschikt omgevingsverrijkend materiaal (Bron: Federale Overheidsdienst Volksgezondheid, Veiligheid van de Voedselketen en Leefmilieu - Dienst Dierenwelzijn). http://www.varkensloket.be/Default.aspx?tabid=7448. Accessed 20-82016.

Verburg, G., 2007. Kamervragen afleidingsmateriaal voor varkens. [Parliamentary questions enrichment materials for pigs]. Available: https://www.rijksoverheid.nl/documenten/kamerstukken/2007/08/14/kamervragenafleidingsmateriaal-voor-varkens. Accessed 1-5-2016, LNV, The Hague.

Verdoes, N., Classens, P., Aarnink, A., 2014. STAR+: dier-en milieuvriendelijke stal. V-focus $11,32-33$.

Vermeer, H., de Greef, K., Houwers, H., 2014. Space allowance and pen size affect welfare indicators and performance of growing pigs under Comfort Class conditions. Livestock Science 159, 79-86.

Weber, R., 2016. Maintaining low stress pig production-rearing pigs with intact tails. Available via https://circabc.europa.eu/faces/jsp/extension/wai/navigation/container.jsp (accessed 21-10-2016). Meeting on actions to prevent tailbiting and reduce tail docking of pigs, 4-6 Oct., 2016, Grange, Ireland. 
Wiepkema, P.R., 1987. Behavioural aspects of stress, Biology of stress in farm animals: an integrative approach, Springer, pp. 113-133.

Wikipedia, 2016. Intelligent Design. Available: https://en.wikipedia.org/wiki/Intelligent_design. Accessed 8-9-2016.

Wikipedia, 2016b. Effective Altruism. Available: https://en.wikipedia.org/wiki/Effective_altruism. Accessed 8-9-2016.

Wikipedia, 2016c. Communicating Vessels. Available: https://en.wikipedia.org/wiki/Communicating_vessels. Accessed 8-9-2016.

Wind, S.M.M., 2012. The Welfare of Organic Finishing Pigs. MSc Thesis University of Utrecht. .

Wind, S.M.M., Bracke, M.B.M., Vermeer, H.M., 2012. The effect of Roughage (i.e. chopped grass silage mixed through the concentrate feed) on welfare of organic growing/finishing pigs. Wageningen Livestock Research. Unpublished report. .

Zonderland, J., Vermeer, H., Vereijken, P., Spoolder, H., 2001. Measuring a Pig's Preference for Suspended Toys by Using an Automated Recording Technique. Available: https://ecommons.cornell.edu/handle/1813/10310. Accessed 14-5-2016, Proceedings of the International Symposium of the C.I.G.R. Animal Welfare Considerations in Livestock Housing Systems, 2nd Technical Section, pp. 147-156.

Zonderland, J.J., 2007. Afleidingsmateriaal breed gewogen. [Enrichment materials widely weighed]. Report. Available: http://library.wur.nl/WebQuery/wurpubs/357049. Accessed 1-5-2016, Wageningen UR Livestock Research, Lelystad.

Zonderland, J.J., Bosma, A.J.J., Hoste, R., 2011. Financiële consequenties van staartbijten bij varkens. [Financial consequences of tail biting in pigs]. Report. Available: http://www.wageningenur.nl/en/Publication-details.htm?publicationId=publication-way343134343230. Accessed 1-5-2016, Wageningen UR Livestock Research, Lelystad. Zonderland, J.J., Wolthuis-Fillerup, M., van Reenen, C.G., Bracke, M.B.M., Kemp, B., Hartog, L.A.d., Spoolder, H.A.M., 2008. Prevention and treatment of tail biting in weaned piglets. Applied Animal Behaviour Science 110, 269-281. 